\title{
COPING ESPIRITUAL RELIGIOSO EM INSTITUIÇÕES De Longa PermanênCia no Norte do Paraná
}

\author{
SPIRITUAL RELIGIOUS COPING IN LONG-TERM CARE FACILITIES \\ IN THE NORTH OF PARANÁ
}

\author{
ENFRENTAMIENTO ESPIRITUAL RELIGIOSO EN ESTABLECIMIENTOS \\ DE LARGA ESTADÍA DEL NORTE DE PARANÁ
}

\author{
Elaine Pinheiro Neves de Macedo* \\ Mary Rute Gomes Esperandio**
}

\begin{abstract}
RESUMO
A mudança de papéis, as perdas e as transformações físicas que caracterizam o contexto da velhice levantam a pergunta sobre o papel da espiritualidade neste cenário. $\mathrm{O}$ estudo objetiva analisar o modo como residentes de Instituições de Longa Permanência para Pessoas Idosas (ILPIs) utilizam a espiritualidade como recurso para o enfrentamento (coping) do estresse e do sofrimento. A pesquisa foi realizada em 18 ILPIs da região Norte do Paraná, com 188 participantes. Trata-se de um estudo descritivo, com abordagem quantitativa com estudo de campo de corte transversal. Os dados foram coletados a partir da aplicação da Escala de Coping Espiritual Religioso (CER BREVE), da Escala da Centralidade da Religiosidade e questionário sociodemográfico. Os resultados apontam média da amostra do CER Positivo ( $M=4,14$ e $D P=0,78)$ e o CER Negativo $(M=1,23$ e $D V=0,49)$. A amostra analisada $(4,0$ a 5,0$)$ indica que a religiosidade é central na vida da pessoa idosa institucionalizada, considerada altamente religiosa. Conclui-se que as pessoas idosas reconhecem a importância da espiritualidade/religiosidade e se beneficiam dela para enfrentar os problemas e superá-los. Fornecer treinamento para o cuidado espiritual de pessoas idosas pode ser uma grande contribuição da Teologia a fim de promover melhores cuidados em ILPIs.
\end{abstract}

Palavras-chave: Coping. Espiritualidade. Religiosidade. Pessoa idosa. Instituição de longa permanência para pessoas idosas.

\section{ABSTRACT}

The change in life roles, losses and physical changes that characterize the context of old age raise the issue about spirituality in this scenario. The study is aimed at analyzing the way in which older people living in Long-Term Care Facilities (LTCF) use spirituality as a coping resource to face stress and suffering. The research was carried out in 18 LTCF in Northern Paraná, with 188 participants. This is a descriptive, quantitative approach and cross-sectional study. The data were collected from the application of the Religious Spiritual Coping Scale (Brief SRCOPE scale),

\footnotetext{
* Doutora em Teologia pela Pontifícia Universidade Católica do Paraná. Mestre em Metodologia para o Ensino de Linguagens e suas Tecnologias na Universidade Norte do Paraná. Professora no Curso de Especialização em Gerontologia na Universidade Tecnológica Federal do Paraná. Brasil. ORCID: 00oo-0002-4414-8117. Email: elaine.pnm@gmail.com.

** Doutora e mestre em teologia pela Escola Superior de Teologia. Professora adjunta no Programa de PósGraduação em Teologia e no Programa de Pós-Graduação em Bioética da Pontifícia Universidade Católica do Paraná. Brasil. ORCID: 0000-0001-8521-8794. E-mail: mary.esperandio@pucpr.br.
} 
the Centrality of Religiosity Scale and a sociodemographic questionnaire. The average of the Positive Spiritual Religious Coping (PSRC) sample was $(M=4.14$ and $S D=0.78)$ and the Negative Religious Spiritual Coping (NSRC) $(M=1.23$ and DV = 0.49). The analyzed sample (4.O to 5.0) indicates that religiosity is central in the lives of the institutionalized elderly, which is considered highly religious. It is concluded that elderly people acknowledge the importance of $S / R$ and benefit from it to face problems and overcome them. Training people for the spiritual care of older people would be a great contribution of theology in promoting better care in LTCF.

Keywords: Coping. Spirituality. Religiosity. Elderly. Long-term care facility for the elderly.

\section{RESUMEN}

El cambio de roles, las pérdidas y los cambios físicos que caracterizan el contexto de la vejez plantean la pregunta sobre el papel de la espiritualidad en este escenario. El estudio tiene como objetivo analizar cómo los residentes de Establecimientos de Larga Estadía para Adultos Mayores (ELEAM) utilizan la espiritualidad como un recurso para afrontar (coping) el estrés y el sufrimiento. La investigación se llevó a cabo en 18 ELEAMs en el norte de Paraná, con 188 participantes. Se trata de un estudio descriptivo, con enfoque cuantitativo y un estudio de campo de corte transversal. Los datos fueron recolectados de la aplicación de la Escala de Afrontamiento (Coping) Espiritual Religioso (CER BREVE), la Escala de Centralidad de Religión y un cuestionario sociodemográfico. Los resultados muestran un promedio de la muestra CER positiva $(M=4.14 \mathrm{y}$ $S D=0.78)$ y la CER negativa $(M=1.23$ y $D V=0.49)$. La muestra analizada (4.0 a 5.o) indica que la religiosidad es central en la vida del anciano institucionalizado, considerado altamente religioso. Se concluye que las personas mayores reconocen la importancia de la espiritualidad /religiosidad y se benefician de ella para afrontar los problemas y superarlos. Dar formación para el cuidado espiritual de las personas mayores puede ser un gran aporte de la Teología para promover una mejor atención en los ELEAMs.

Palabras Clave: Enfrentamiento. Espiritualidad. Religiosidad. Anciano. Establecimiento de Larga Estadía para Adultos Mayores.

\section{INTRODUÇÃO}

Nos últimos anos, tem ocorrido um aumento no envelhecimento populacional. O que antes era percebido nos países desenvolvidos, hoje se apresenta nos países em desenvolvimento, como o Brasil. Tais mudanças têm provocado alterações significativas na vida dos indivíduos, tanto para a pessoa idosa quanto para as famílias.

Diante das dificuldades em prover o cuidado à familiares idosos no contexto familiar, as Instituições de Longa Permanência passaram a ser uma alternativa (CAMARANO; KANSO, 2010; REIS et al., 2013; OLIVEIRA; ROZENDO, 2014). Essas Instituições são “[...] governamentais ou não governamentais de caráter residencial, destinadas a serem domicílios coletivos de pessoas com idade igual ou superior a 60 anos, com ou sem suporte familiar, em condição de liberdade, dignidade e cidadania.” (AGÊNCIA NACIONAL DE VIGILÂNCIA SANITÁRIA, 2005, p. 2).

Conforme Camarano e Kanso (2010), as pessoas veem as ILPIs (Instituições de Longa Permanência para Idosos) com certo preconceito, como um local de segregação. No entanto, 
o modo como se dá o ingresso da pessoa idosa em ILPIs depende de vários aspectos, dentre eles, o posicionamento da própria família. Também a pessoa que envelhece enfrenta desafios, um destes é deixar o convívio da família para entrar em uma instituição. A pessoa idosa se percebe em meio a mudanças, no sentido de perda de autonomia, súbita troca de ambiente, e a necessidade de estabelecer novas relações. A soma de experiências é que vai determinar o grau de aceitação e de adaptação aos novos processos e formas de vida que se apresentam. Assim, cada indivíduo idoso, submetido à internação em ILPIs apresentará diferentes graus de dificuldade no processo de adaptação ou de enfrentamento.

O presente estudo objetiva analisar o modo como residentes de ILPIs no Norte do Paraná utilizam-se da espiritualidade como recurso para o enfrentamento (coping) do estresse e do sofrimento. Neste sentido, utilizamos como ferramenta metodológica uma pesquisa descritiva e quantitativa; um estudo de campo de corte transversal, realizado em 18 ILPIs da região Norte do Paraná, com 188 participantes. Os dados foram coletados a partir da aplicação da Escala CER BREVE, da Escala da Centralidade da Religiosidade (ECR) e de um questionário sociodemográfico.

\section{ESPIRITUALIDADE, RELIGIOSIDADE E RELIGIÃO - CONCEITOS}

Os termos espiritualidade, religiosidade e religião são por vezes confundidos, ocasionando equívocos e podem distanciar-se dos seus verdadeiros significados. No geral, a espiritualidade pode ser conceituada como uma busca de sentido e "[...] do significado, do propósito e da verdade na vida, paz interior, conforto, conexão com os outros, bem como as crenças e os valores de acordo com as quais uma pessoa vive.” (KOENIG, 2012, p. 13).

Gomes, Farina e Dal Forno (2014) afirmam que a espiritualidade é afeita às questões humanas mais profundas como as perguntas existenciais: de onde vim? Para onde vou? Que propósito tem minha vida? Enquanto a religiosidade está ligada à “[...] expressão prática, às experiências místicas.” (GOMES; FARINA; DAL FORNO, 2014, p. 110).

A palavra religião é proveniente do latim religio e ligare e significa “[...] ligar de novo"; o conceito refere ao aspecto institucional e doutrinário (OLIVEIRA; JUNGES, 2012, p. 470). Koenig assinala que "[...] a religião costuma oferecer um código moral de conduta que é aceito por todos os membros da comunidade." (KOENIG, 2012, p. 11).

Quanto à religiosidade, Koenig (2012) a define como atividade religiosa, podendo ser: a) organizacional, aquela cujo membro se “[...] envolve na participação de serviços religiosos com outras pessoas relacionadas à igreja [...]”; b) não organizacional, a que se refere à “[...] atividade religiosa realizada a sós, em particular, como exemplo, orar ou comunicar-se com 
Deus em casa." (KOENIG, 2012, p. 11). Para Koenig (2012) a espiritualidade de modo amplo é uma parte complexa e multidimensional da experiência humana. Nesse sentido, Peres, Simão e Nasello destacam que "[...] o interesse sobre a espiritualidade e a religiosidade sempre existiu no curso da história humana, [...]. Contudo, apenas recentemente a ciência tem demonstrado interesse em investigar o tema." (PERES; SIMÃO; NASELLO, 2007, p. 137).

É possível observar que a espiritualidade/religiosidade (E/R) são recursos utilizados pela pessoa idosa no seu dia a dia, "[...] no sentido de buscar apoio para as situações estressantes, distância da família, problemas de saúde e a própria institucionalização." (VITORINO; VIANNA, 2012, p. 137). Por vezes, o adoecimento e a cura são atribuídos ao ser superior, ao transcendente, o que leva a estratégias em que o indivíduo apela ao transcendente com o intuito de alcançar uma melhoria no seu estado de saúde. Desta forma, a busca de sentido estimula as pessoas idosas a superar e a entender as dificuldades que surgem durante a vida na institucionalização.

Portanto, se percebe a possibilidade da contribuição da Teologia, Pública e Prática, que se efetiva na esfera pública, nesse caso em ILPIs. Ou seja, a Teologia pode dedicar-se às pessoas mais vulneráveis e ajudá-las a viver dignamente durante o envelhecimento.

\subsection{Coping espiritual/religioso}

Kenneth Pargament (1997) foi um dos pioneiros da sistematização da teoria sobre coping religioso/espiritual. A partir de discussões argumentadas e debatidas sobre a espiritualidade, passou a usar a expressão coping espiritual/religioso (CER). Coping significa enfrentamento ou lidar com (ESPERANDIO et al., 2019).

O CER refere-se à utilização de elementos sagrados na forma de responder aos eventos estressores, sendo que os métodos podem ser positivos ou negativos (PARGAMENT; KOENIG; PEREZ, 1998). O que compõe um padrão de CER Positivo são os métodos de enfrentamento com configuração positiva frente a Deus; coping religioso colaborativo; busca de suporte espiritual, transformação de vida, dentre outros (PARGAMENT; KOENIG; PEREZ, 1998, p. 712). Já o CER Negativo expressa-se por meio de um relacionamento menos seguro com Deus; uma visão de mundo frágil e ameaçadora, e conflitos espirituais na busca por significado (PARGAMENT; KOENIG; PEREZ, 1998, p. 712). 
O CER está ligado aos comportamentos e crenças apresentados pelas pessoas, cujo objetivo é o de favorecer a resolução de problemas, prevenir ou aliviar consequências emocionais negativas de eventos estressantes (KOENIG; PARGAMENT; NIELSEN, 1998; FARIA; SEIDL, 2005; PANZINI; BANDEIRA, 2007; GOBATTO; ARAUJO, 2010; HAGHIGHI, 2013).

Alguns estudos têm demonstrado que o impacto da $\mathrm{E} / \mathrm{R}$ e das crenças pessoais influencia no processo de envelhecimento, especialmente frente às doenças, fim de vida e ainda em situação de internamento em ILPIs. Vitorino e Vianna (2012), realizaram uma pesquisa com 77 internos em duas ILPIs, os resultados mostraram que a capacidade das pessoas idosas de lidar com situações adversas está intimamente ligada à utilização de recursos espirituais/religiosos. Observou-se, inclusive, a melhora na capacidade funcional em atividades do dia-a-dia.

As necessidades espirituais crescem de significado à medida que se aproxima a finitude. A partir do estudo realizado por Esperandio e colaboradores (2017, p. 303), com um grupo de quarenta indivíduos que possuem parentes em Unidade de Tratamento Intensivo, vê-se que 60\% utilizaram-se da religião como principal forma de enfrentamento. Ou seja, “[...] espiritualidade/religiosidade é um fator expressivo no enfrentamento de situações em que a vida é ameaçada, sendo relevante sua integração nas práticas de cuidado pela equipe multidisciplinar hospitalar.” (ESPERANDIO et al., 2017, p. 303).

Pela significância que a pessoa idosa atribui às suas crenças espirituais ou suas práticas religiosas, especialmente pelas situações complexas que a idade traz, como por exemplo, a doença, sugere-se a necessidade de novas pesquisas, desde o cuidado humanizado até a inserção de disciplinas na formação dos profissionais de saúde acerca da temática E/R (DUARTE; WANDERLEY, 2011; OLIVEIRA; ALVES, 2014).

No Brasil, as pesquisas sobre CER tiveram sua origem com Panzini (2004) e Panzini e Bandeira (2007) obtendo a validação da escala de CER, produzida por Pargament, Koenig e Perez (2000). Considerando os resultados levantados em pesquisas e baseados em evidências, os resultados apontam para a necessidade da sistematização de uma escala de medida mais breve do que as originalmente construídas (ESPERANDIO et al., 2019, p. 271). Assim, Pargament (1997) desenvolveu uma versão breve, com 14 itens, tendo sido validada no Brasil por Esperandio e Machado (2018). 


\subsection{Escala coping espiritual/religioso (escala CER-BREVE 14)}

A Escala CER-BREVE 14 mede o CER Positivo e o CER Negativo. Conforme Esperandio e colaboradoras, o CER Positivo consiste, no sentido da espiritualidade, a "[...] um relacionamento seguro com Deus, a crença de que existe um sentido na vida para ser buscado e senso de conexão com os outros.” (ESPERANDIO et al., 2019, p. 271). Enquanto o CER Negativo "[...] expressa-se por meio de um relacionamento menos seguro com Deus, uma visão de mundo frágil e ameaçadora e indica a presença de conflitos espirituais.” (ESPERANDIO et al., 2019, p. 271). As alternativas são apresentadas para medir a intensidade, por meio da Escala Likert: Nem um pouco/Nunca; Um pouco; Mais ou Menos; Bastante e Muitíssimo. As quatorze afirmações da escala buscam aferir dois tipos de CER, ambos com sete afirmações, que podem ser visualizadas na tabela a seguir.

\section{Tabela 1 - Estratégias CER Positivo e CER Negativo}

\begin{tabular}{|l|}
\hline \multicolumn{1}{|c|}{ Estratégias de Coping Espiritual Religioso Positivo } \\
\hline 1. Procurei uma ligação maior com Deus \\
\hline 2. Procurei o amor e a proteção de Deus \\
\hline 3. Busquei ajuda de Deus para livrar-me da minha raiva \\
\hline 4. Tentei colocar meus planos em ação com a ajuda de Deus \\
\hline 5. Tentei ver como Deus poderia me fortalecer nesta situação \\
\hline 6. Pedi perdão por meus erros ou pecados \\
\hline 7. Foquei na religião para parar de me preocupar com meus problemas \\
\hline Estratégias de Coping Espiritual Religioso Negativo \\
\hline 1. Fiquei imaginando se Deus tinha me abandonado \\
\hline 2. Senti-me punido por Deus pela minha falta de fé \\
\hline 3. Fiquei imaginando o que eu fiz para Deus me castigar \\
\hline 4. Questionei o amor de Deus por mim \\
\hline 5. Fiquei imaginando se meu grupo religioso tinha me abandonado \\
\hline 6. Cheguei à conclusão de que forças do mal atuaram para isso acontecer \\
\hline 7. Questionei o poder de Deus \\
\hline
\end{tabular}

Fonte: (ESPERANDIO et al., 2019, p. 273). 
Os parâmetros de interpretação são Nenhuma/Irrisória (1,00 a 1,50), Baixa (1,51 a 2,50), Média (2,51 a 3,50), Alta (3,51 a 4,50) e Altíssima (4,51 a 5,00).

\subsection{Escala da Centralidade da Religiosidade}

Cada vez mais, a religiosidade tem sido investigada no que se refere à saúde. Segundo Moreira-Almeida e Koenig (2006), os resultados têm apontado positivamente para a relação entre envolvimento religioso e saúde. A escala foi validada para o contexto brasileiro (altamente religioso), verificou-se a confiabilidade e a multidimensionalidade da ECR, pois pode ser usada: “[...] não apenas para verificar a centralidade da religiosidade na vida dos indivíduos, mas também para prever ou explicar certas formas de comportamento humano nas quais a variável religiosidade desempenha um papel importante." (ESPERANDIO et al., 2019, p. 2). Concluem as autoras que a versão pode ser considerada adequada para "[...] uso na população brasileira, quando o contexto exige uma coleta de dados mais simples e rápida." (ESPERANDIO et al., 2019, p. 11).

A escala possui 10 itens e foi utilizada com objetivo de verificar se realmente a religiosidade se apresenta como dimensão central na amostra da população idosa analisada. Os parâmetros da ECR são as variáveis: Altamente Religioso (4,0 a 5,0), Religioso (2,1 a 3,9), Não Religioso (1,o a 2,0). A sistematização da análise dos dados quantitativos foi realizada por meio do programa Statistical Package for the Social Sciences (SPSS 21).

\section{METODOLOGIA}

A pesquisa, ${ }^{1}$ foi realizada com abordagem quantitativa analítica, a partir de uma pesquisa de campo de corte transversal, descritiva e exploratória (FONTELLES et al., 2009, p. 5). No que tange ao recorte geográfico da pesquisa, optou-se pelo enfoque das cidades que compõem o Norte Central e o Norte Pioneiro do Paraná. Para tanto, foram utilizadas informações do Instituto Brasileiro de Geografia e Estatística, as quais indicaram quarenta e oito cidades no Norte Pioneiro e setenta e nove no Norte Central (IBGE, 2016). O critério de escolha foi conforme o número maior de habitantes/cidades.

\footnotetext{
${ }^{1}$ A pesquisa apresentada neste manuscrito foi aprovada pelo Comitê de Ética em Pesquisa da Pontifícia Universidade Católica do Paraná, no Parecer 2.235.357, de 23 agosto de 2017. Inicialmente, a pesquisadora estabeleceu contato pessoal com a equipe dirigente das Instituições selecionadas para o estudo. Nestas ocasiões, era apresentada a proposta de trabalho, objetivando o consentimento da equipe dirigente para a realização da pesquisa. Essa fase exploratória e as entrevistas foram conduzidas nos meses de setembro à novembro de 2017.
} 
Em um segundo momento, fez-se o contato com as Prefeituras dos municípios e com a Secretaria do Idoso, com o intuito de obter a relação das ILPIs que tivessem registro no Conselho Municipal de Direitos do Idoso. Foram excluídas da pesquisa as instituições conhecidas como Centro Dia, por não proporcionarem a permanência total da pessoa idosa. $\mathrm{Na}$ sequência, realizou-se uma sondagem por meio de contato telefônico com cada coordenador das ILPIs. Nesses contatos, foram obtidas informações que se referem: ao número de idosos masculinos e femininos, a faixa etária e o número de idosos passíveis de serem entrevistados. Foram excluídas da pesquisa, pessoas idosas com Alzheimer, demência ou outra enfermidade que impossibilitasse a entrevista, e incluídas pessoas idosas com sessenta anos ou mais, com capacidade cognitiva de responder às questões da entrevista.

A coleta de dados com cada pessoa idosa participante do estudo foi realizada pela primeira autora deste manuscrito, em espaço privativo. Iniciava-se conversando sobre diversos assuntos (já com ciência do histórico da pessoa a ser entrevistada). Só depois de perceber que o/a participante estava tranquilo/a, sentindo-se à vontade, dava-se início à entrevista, permeada pelas questões dos instrumentos supracitados.

Foram utilizados para coleta de dados: 1) Questionário sociobiodemográfico para pessoas idosas, sendo acrescentadas ainda questões como: motivo e tempo de institucionalização e sobre a frequência de visitação; 2) Escala CER-BREVE 14 (ESPERANDIO; MACHADO, 2018), e 3) Escala ECR (10 itens) (ESPERANDIO et al., 2019).

De modo geral, no caso das instituições filantrópicas, a pessoa idosa recrutada para participar foi indicada pela assistente social; já nas instituições privadas, a indicação dos entrevistados foi realizada pelos gestores das mesmas.

\section{RESULTADOS}

Foram selecionadas para a pesquisa vinte e seis ILPIs, destas, seis não autorizaram o estudo (uma filantrópica e cinco privadas, todas da cidade de Londrina). Além disso, duas foram excluídas em razão de que lá estavam apenas pessoas idosas com Alzheimer. Das dezoito ILPIs escolhidas, nove são instituições filantrópicas e nove privadas, de grande e de pequeno porte. A maioria delas conta com equipe multiprofissional. Apenas uma instituição não inclui em seu quadro de funcionários uma equipe voltada aos cuidados de saúde, isto é, trabalhando como cuidadores de pessoas idosas. Ou seja, as mesmos funcionários fazem a limpeza, cozinham e atendem as pessoas idosas, realizando diferentes funções: troca de fraldas, auxílio durante o banho e no uso dos medicamentos, além de acompanhar (em alguns casos) os institucionalizados aos hospitais ou postos de saúde. 
No que se refere aos dados sociodemográficos, das cento e oitenta e oito pessoas idosas participantes, noventa e cinco (50,53\%) são do sexo feminino e noventa e três $(49,47 \%)$ do sexo masculino. A média de idade constatada foi de 70 à 80 anos. Quanto ao estado civil, observou-se um número significativo de pessoas solteiras $(32,45 \%)$ e de viúvas $(38,30 \%)$.

Ao tratar da escolaridade, a maioria das pessoas idosas (67,02\%) tem Ensino Fundamental, as demais são analfabetas (23,40\%). Ao serem questionadas sobre se haviam tido filhos/as, predominou a resposta sim (63.83\%), dado relevante, pois se reflete na questão que diz respeito ao motivo de institucionalização evidenciada no gráfico 1. O referido gráfico aponta que a institucionalização é promovida em maior número pela família, amigos/as e parentes.

\section{Gráfico 1 - Motivo de Institucionalização}

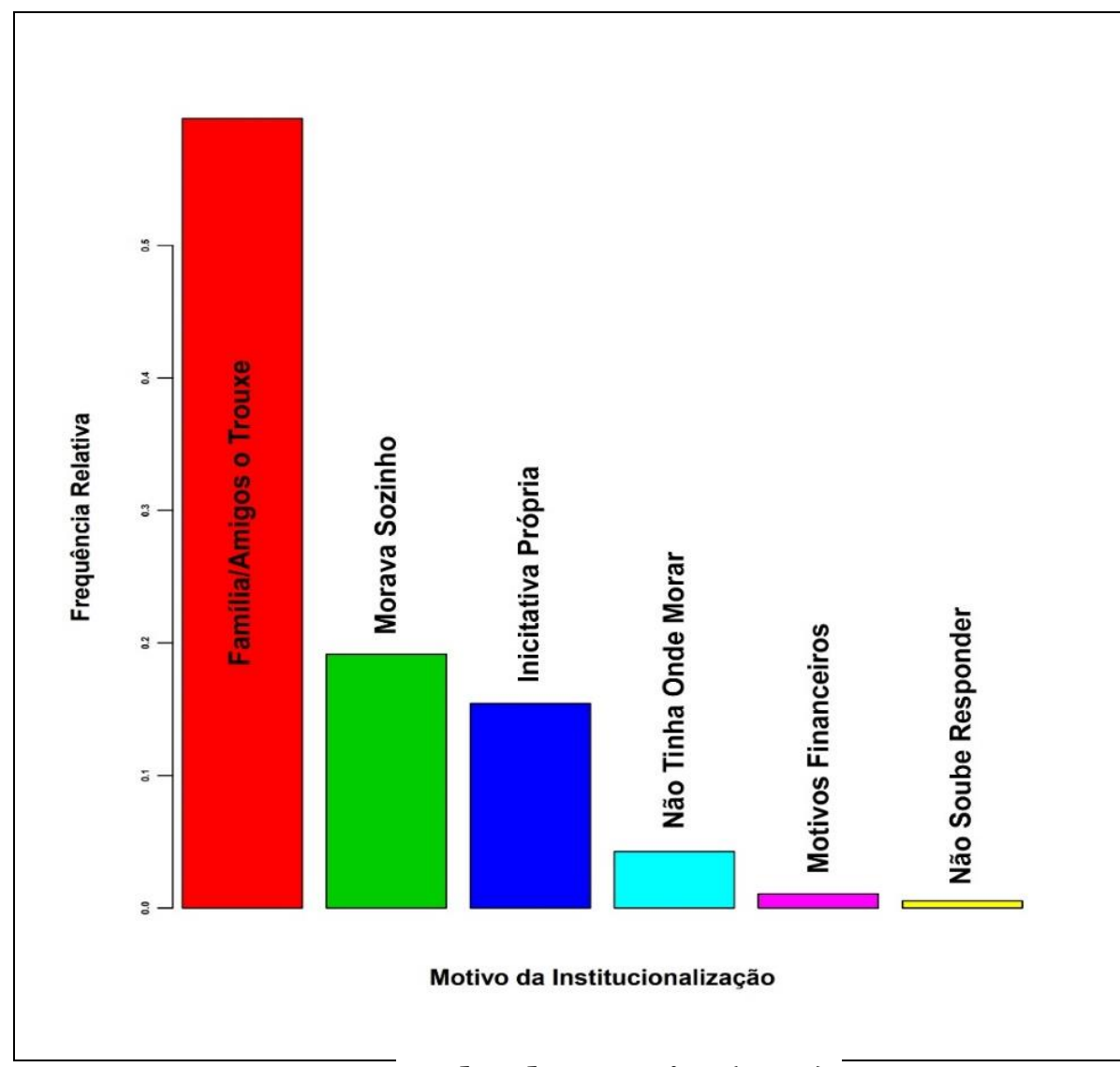

Fonte: Dados da Pesquisa (2017).

No aspecto receber visitas, houve equilíbrio, sendo mais pontuada a variável algumas vezes, com 24,47\%; mas, conforme observado por ocasião das coletas empíricas, quando a pessoa idosa responde que recebe visitas, isso inclui não apenas a família mas também 
pessoas desconhecidas que realizam visitas à Instituição. Em adição, conta-se com horários e dias determinados (na maioria, o domingo) para qualquer tipo de visita com atividades. Das dezoito ILPIs visitadas, apenas uma (na cidade de Cornélio Procópio) é aberta aos institucionalizados em tempo integral, contexto em que, algumas pessoas idosas podem sair, caminhar ou ir ao culto ou à missa.

O questionamento sobre sentir-se só ficou equilibrado, com as seguintes respostas: sempre (19,68\%); muitas vezes (16,49\%); algumas vezes (19,15\%) raramente $(21,28 \%) \mathrm{e}$ nunca (23,40\%). No que concerne à variável participação em atividades, muitas das pessoas idosas não participam de atividades (física ou cultural). A partir disso, a pesquisa constatou um grande número de pessoas incapacitadas fisicamente, sendo que muitas delas são cadeirantes, algumas acamadas, e outras quase inativas em decorrência da falta de profissionais dedicados a tais atividades.

No item afiliação religiosa (Gráfico 2), cento e setenta e três pessoas idosas entrevistadas declararam-se como católicas (92,51\%). De modo mais específico, a administração das dezoito ILPIs é conduzida por: (1) Pastor Evangélico; (1) Espírita, (7) profissionais da saúde - enfermeiras e (9) congregações da Igreja Católica.

\section{Gráfico 2 - Afiliação Religiosa dos idosos internalizados}

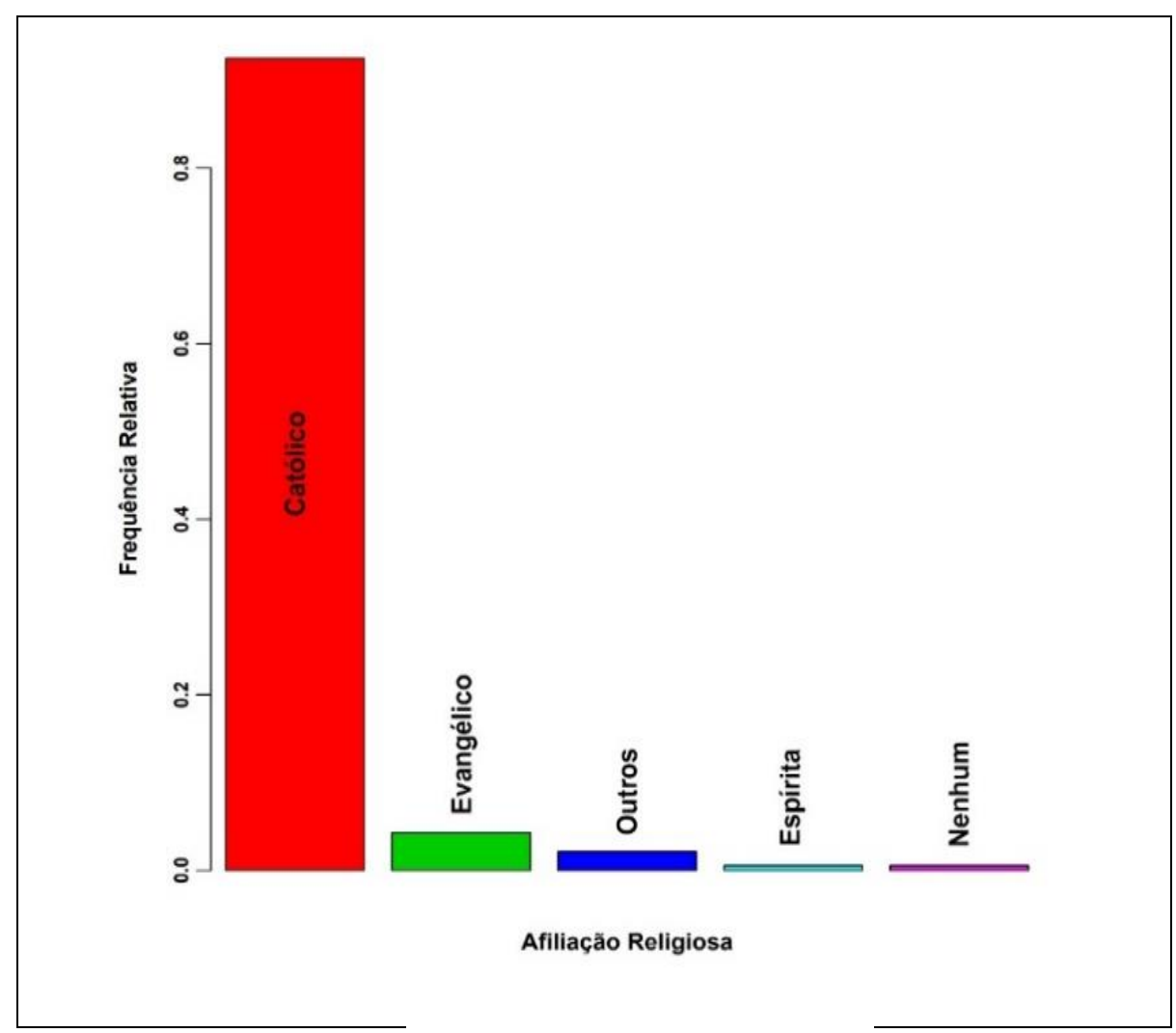

Fonte: Dados da Pesquisa (2017). 
Por fim, ao tratar do tempo de institucionalização, os resultados apontam que, dentre as cidades que abrigam as ILPIs pesquisadas (Apucarana, Arapongas, Bandeirantes, Cornélio Procópio, Jacarezinho, Londrina, Rolândia e Santo Antônio da Platina), a cidade de Jacarezinho sobressaiu-se pelo fato de contar com residentes que estão há mais tempo institucionalizados (cerca de vinte anos). Com isso, confirma-se a existência de ILPIs na região Norte Pioneira do Paraná há bastante tempo.

No que concerne ao CER, conforme os parâmetros de Interpretação da Escala CERBREVE, a partir da Tabela 2 e do Quadro 1, foi possível verificar a Média, a Mediana e o Desvio Padrão do CER Positivo. A média sinalizada foi de 4,00, o que reflete o parâmetro Alto; enquanto que a média 1,23 no CER Negativo indica o parâmetro Nenhuma/Irrisória, no uso de estratégia do CER.

Tabela 2 - Fatores

\begin{tabular}{|c|c|c|c|}
\hline Variável & Média & Mediana & $\begin{array}{l}\text { Desvio } \\
\text { Padrão }\end{array}$ \\
\hline 1. Procurei uma ligação maior com Deus & 4,18 & 4,00 & 0,84 \\
\hline 2. Procurei o amor e a proteção de Deus & 4,21 & $4, \mathrm{OO}$ & 0,85 \\
\hline $\begin{array}{l}\text { 3. Busquei ajuda de Deus para livrar-me da } \\
\text { minha raiva }\end{array}$ & 4,03 & 4,00 & 0,95 \\
\hline $\begin{array}{l}\text { 4. Tentei colocar meus planos em ação com a } \\
\text { ajuda de Deus. }\end{array}$ & 3,95 & 4,00 & 0,87 \\
\hline $\begin{array}{l}\text { 5. Tentei ver como Deus poderia me fortalecer } \\
\text { nesta situação. }\end{array}$ & 3,93 & 4,00 & 0,84 \\
\hline 6. Pedi perdão pelos meus erros (ou pecados) & 3,97 & $4, \mathrm{OO}$ & 1,04 \\
\hline $\begin{array}{l}\text { 7. Foquei na religião para parar de me preocupar } \\
\text { com meus problemas. }\end{array}$ & 3,74 & $4, \mathrm{OO}$ & 0,96 \\
\hline $\begin{array}{l}\text { 8. Fiquei imaginando se Deus tinha me } \\
\text { abandonado }\end{array}$ & 1,29 & 1,00 & 0,78 \\
\hline $\begin{array}{l}\text { 9. Senti-me punido por Deus pela minha falta de } \\
\text { fé }\end{array}$ & 1,19 & 1,00 & 0,53 \\
\hline $\begin{array}{l}\text { 10. Fiquei imaginando o que eu fiz para Deus me } \\
\text { castigar }\end{array}$ & 1,20 & 1,00 & 0,60 \\
\hline 11. Questionei o amor de Deus por mim & 1,22 & 1,00 & 0,53 \\
\hline $\begin{array}{l}\text { 12. Fiquei imaginando se meu grupo religioso } \\
\text { tinha me abandonado. }\end{array}$ & 1,39 & 1,00 & 0,80 \\
\hline $\begin{array}{l}\text { 13. Cheguei à conclusão de que forças do mal } \\
\text { atuaram para isso acontecer }\end{array}$ & 1,15 & 1,00 & 0,48 \\
\hline 14. Questionei o poder de Deus & 1,15 & 1,00 & 0,50 \\
\hline
\end{tabular}

Fonte: Dados da Pesquisa (2017). 


\section{Quadro 1 - Média, Mediana e Desvio Padrão}

\begin{tabular}{|l|l|l|l|}
\hline & Média & Mediana & $\begin{array}{l}\text { Desvio } \\
\text { Padrão }\end{array}$ \\
\hline Coping Espiritual Religioso Positivo & 4,00 & 4,14 & 0,78 \\
\hline Coping Espiritual Religioso Negativo & 1,23 & 1,00 & 0,49 \\
\hline
\end{tabular}

Fonte: Dados da Pesquisa (2017).

A ECR avalia se a religiosidade é central na vida da pessoa idosa. O levantamento desses dados viabiliza a verificação de quais dimensões são mais representativas do comportamento religioso, sejam elas de ordem intelectual, ideológica, prática pública, prática privada ou experiência religiosa, conforme a Tabela 3.

Tabela 3 - Escala de Centralidade da Religiosidade

\begin{tabular}{|c|c|c|c|}
\hline Variável & Média & Mediana & $\begin{array}{l}\text { Desvio } \\
\text { Padrão }\end{array}$ \\
\hline $\begin{array}{l}\text { ITEM } 1 \text { - Com que frequência você costuma participar de } \\
\text { serviços religiosos? }\end{array}$ & 5,60 & 6,00 & 1,28 \\
\hline \multicolumn{4}{|l|}{ ITEM 2} \\
\hline $\begin{array}{l}\text { Quanto você se interessa em aprender sobre assuntos } \\
\text { religiosos? }\end{array}$ & 4,05 & 4,00 & 1,01 \\
\hline Qual é a importância da oração pessoal para você? & 4,24 & 4,00 & 0,87 \\
\hline $\begin{array}{l}\text { Até que ponto você acredita na existência de Deus ou de algo } \\
\text { divino? }\end{array}$ & 4,51 & 5,00 & 0,86 \\
\hline $\begin{array}{l}\text { Que importância tem para você a participação em atividades } \\
\text { religiosas? }\end{array}$ & 4,03 & 4,00 & 0,94 \\
\hline $\begin{array}{l}\text { Até que ponto você acredita em vida após a morte - por } \\
\text { exemplo, imortalidade da alma, ressurreição ou } \\
\text { reencarnação? }\end{array}$ & 3,93 & 4,00 & 1,23 \\
\hline \multicolumn{4}{|l|}{ ITEM 3 - Com que frequência } \\
\hline Você pensa sobre questões religiosas? & 3,99 & 4,00 & 0,90 \\
\hline $\begin{array}{l}\text { Você passa por situações nas quais tem o sentimento de que } \\
\text { Deus ou alguma coisa divina quer comunicar-se ou revelar } \\
\text { alguma coisa para você? }\end{array}$ & 4,10 & 4,00 & 0,91 \\
\hline $\begin{array}{l}\text { Você passa por situações nas quais tem o sentimento de que } \\
\text { Deus ou um ser superior intervém em sua vida? }\end{array}$ & 4,13 & 4,00 & 0,90 \\
\hline ITEM 4 - Com que frequência você normalmente ora/reza? & 8,20 & 8,00 & 1,25 \\
\hline
\end{tabular}

Fonte: Dados da Pesquisa (2017). 


\section{DISCUSÃO}

De acordo com os resultados sociodemográficos, a amostra revelou maior número de pessoas na faixa etária de sessenta à setenta anos. Nos resultados obtidos com o uso da Escala CER-BREVE (Tabela 1), evidenciou-se que as estratégias do CER Positivo mais utilizadas foram Procurei o amor e a proteção de Deus (4,21); Procurei uma ligação maior com Deus (4,18) e Busquei ajuda de Deus para livrar-me da minha raiva (4,03), indicando o parâmetro alto. Com tais resultados, é possível compreender que a pessoa idosa institucionalizada demonstra valores relacionados ao transcendente, na pretensão de que possa estabelecer razões para viver, ou seja, dar um sentido para a vida.

Conforme sugerem os resultados da Tabela 1, no que tange ao CER Negativo, as variáveis mais recorrentes são: Fiquei imaginando se meu grupo religioso tinha me abandonado (1,39); Fiquei imaginando se Deus tinha me abandonado (1,29); Questionei o amor de Deus por mim (1,22); Cheguei à conclusão de que forças do mal atuaram para isso acontecer $(1,15)$ e Questionei o poder de Deus $(1,15)$. Verificou-se que o CER Positivo prevalece em relação ao CER Negativo, isto é, a pessoa idosa busca, por meio da espiritualidade, um relacionamento salutar junto ao transcendente, a fim de resolver seus conflitos. Pargament, Koenig e Perez (2000) assinalam que o CER Positivo e o CER Negativo explicam as correlações existentes. Para eles, quanto maior e intensa for a fé da pessoa idosa institucionalizada, maior será a aceitação, a compreensão e o enfrentamento dos desafios cotidianos.

Segundo Panzini e Bandeira o CER, que descreve o "[...] modo como os indivíduos utilizam sua fé para lidar com o estresse, tem-se mostrado associado a melhores índices de qualidade de vida e saúde física e mental.” (PANZINI; BANDEIRA, 2005, p. 507). A partir de tal afirmativa, foi possível observar que a pessoa idosa institucionalizada passa por várias situações de crise (as doenças, o envelhecimento e as perdas, o sentir-se como estorvo, como inútil, como incapacitado, como abandonado pela família). Ao serem perguntados: Fiquei imaginando se Deus tinha me abandonado (média=1,29), muitos disseram: "Jamais, nunca, mas pela família sim.” (informação verbal). Tal resposta relaciona-se com o Gráfico 1, que aponta que 59,57\% das pessoas idosas entrevistadas foram conduzidas por familiares às ILPIs. Durante as entrevistas, houve manifestação de sofrimento e estresse pela maioria das pessoas participantes; estratégias religiosas de coping foram utilizadas diante dessas situações, o que confirma o resultado da variável: Foquei na religião para parar de me preocupar com meus problemas (média=3,74 e mediana=4,00). 
Corroborando esta afirmação, Rocha e Ciosak (2014) em estudo para compreender o papel da espiritualidade de 20 pessoas idosas, mostraram que a "[...] espiritualidade/religiosidade/ e a fé interferem de modo positivo no enfrentamento dos obstáculos e dificuldades da vida, fortalecem a resiliência do paciente, melhorando, assim, sua qualidade de vida." (ROCHA; CIOSAK, 2014, p. 92). Estudos recentes (JUN et al., 2015; NUNES et al., 2015; STECZ; KOCUR, 2015; VITORINO; LOW; VIANNA, 2016; GHOLAMI et al., 2017) têm mostrado sua relevância na temática da espiritualidade. Têm sido cada vez mais investigadas as relações entre $\mathrm{E} / \mathrm{R}$ e saúde, bem como o quanto interferem de maneira positiva na saúde física e mental da pessoa idosa (GOBATTO; ARAUJO, 2010; VITORINO; VIANNA, 2012). As crenças e comportamentos religiosos ajudam a enfrentar o sofrimento experimentado nas ILPIs, e servem como recursos para a prevenção, o alívio, e possível superação do estresse (LUCHETTI et al., 2011; SANTOS et al., 2013).

Desse modo pode-se inferir que os participantes utilizam do CER como forma de lidar com o estresse. Neste contexto, vale mencionar que segundo Pargament (2013) apesar de a E/R ser utilizada como recurso de coping tanto de modo positivo quanto negativo, os resultados desse estudo sugerem que a pessoa idosa faz uso do coping espiritual/religioso positivo.

Quanto a ECR, o levantamento desses dados viabilizou a verificação de quais dimensões (intelectual, ideológica, prática pública, prática privada e experiência religiosa) são mais representativas no comportamento religioso. Ao observar os dados e os resultados da Tabela 2, é possível afirmar que as pessoas idosas institucionalizadas dispensam grande importância à religiosidade em suas vidas. A questão: Com que frequência você normalmente ora/reza? obteve média=8,20, apontando para altamente religioso. Salienta que indivíduos categorizados como altamente religiosos refletem que o sistema religioso ocupa uma posição central, ou seja, as crenças religiosas influenciam nas tomadas de decisão na vida diária.

Outrossim, a variável afiliação religiosa chamou a atenção, considerando um número significativo de católicos; os administradores das ILPIs na maioria também são católicos. Foi observado, na pesquisa de campo, que os internos e as internas, independentemente da confissão religiosa, inclusive cadeirantes, doentes de Alzheimer e pessoas com certo grau de demência, eram levadas à assistir à missa católica televisionada e em seguida participar da reza do terço, uma devoção católica. Pode-se inferir que, a partir da incapacidade de manifestar sua vontade, a pessoa idosa acaba por aceitar outras opiniões e crenças, ocasionando uma violência espiritual. 
No Brasil, a Constituição Federal (BRASIL, 1988), a Lei Federal n, 9.982/2000 (BRASIL, 2000) e as leis estaduais asseguram e regulamentam a assistência religiosa em hospitais, desde que realizada em comum acordo entre pacientes e familiares, o que se aplica ao contexto das ILPIs. Assim, é necessário ter atenção quanto ao proselitismo, ao forçar a presença dos institucionalizados à ritos de determinada religião sem inquirir pela vontade de participar. Pode, inclusive, haver prejuízo da saúde conforme a abordagem religiosa.

Com isso, pode-se até justificar o número expressivo de pessoas idosas que se dizem católicas, dado que pode ser visualizado no gráfico 2. Em outras instituições (administradas por outras denominações religiosas), foi observado o impedimento da entrada de líderes religiosos contrários, por exemplo, a visita do líder religioso (padre), ou a negação de práticas religiosas como a oração do terço, etc.

É possível verificar que a pessoa idosa institucionalizada acredita que a prática da espiritualidade é eficaz, seja na recuperação da saúde, na lida com o sofrimento e com o advento da morte. O que se pode assinalar, diante destes dados, é a relevância da assessoria de uma Teologia Pública e Prática. A falta de liberdade da pessoa idosa, no trato da sua própria fé, nas ILPIs, deve ser evitada. Não são raras as vezes em que doutrinas implantam a ideia de que fora de determinada igreja não há salvação. Alguns teólogos dirão que, diante desta violência espiritual, é preciso questionar o poder religioso e apresentar uma nova dimensão da espiritualidade: a tolerância. Tolerância "[...] é uma atitude de empatia, isto é, 'eu' me coloco no lugar do 'outro' e, 'como se fosse' ele, vivencio indiretamente sua dor, sua fé e sua esperança. O ‘outro’ não deve ser o que 'eu’ gostaria que ele fosse, mas ele mesmo [...]” (SOUZA, 2010, p. 57-58).

Frente aos resultados urge nas ILPIs a presença de Cuidador/a Espiritual. Desta forma, o cuidado espiritual será realizado por um profissional comprometido com o bemestar da pessoa mais vulnerável, da pessoa em sofrimento, que por vezes demanda atenção à sua espiritualidade. Desse modo, o Cuidador estará apto para lidar de melhor forma com os eventos estressores da institucionalização e impedir a imposição de práticas espirituais e/ou crenças diferentes da professada pelo indivíduo idoso institucionalizado.

A Teologia Pública e Prática têm essencialmente a perspectiva de dialogar. Neste caminho, é possível extrair e construir, a partir dos recursos que a pessoa idosa traduz em sua prática diária, ou seja, como ela lida com o novo mundo que a circunda e que muitas vezes a sufoca e lhe traz sofrimentos. Dessa forma, defende-se o lugar de prática teológica.

Na idade avançada a dimensão espiritual constitui um fator de resiliência. O estudo de Grangeiro e colaboradores (2017) indica a religiosidade como fator de impacto positivo 
para as pessoas idosas, assim como no presente estudo. Nesse contexto, os dados confirmam o quanto a pessoa idosa busca, na dimensão espiritual, apoio para o enfrentamento das situações difíceis do estresse e o quanto se apega ao transcendente, sobretudo, visando preencher o vazio que tanto a inquieta, de forma a proporcionar-lhe sentimento de bemestar. Assim sendo, uma compreensão melhor da temática em foco, auxilia os profissionais da saúde a reconhecer e a valorizar a espiritualidade tendo em vista um cuidado holístico capaz de promover a saúde e o bem-estar da pessoa idosa, especialmente daquelas que vivem em ILPIs.

\section{CONSIDERAÇÕES FINAIS}

As necessidades espirituais crescem de significado na medida em que se aproxima a finitude. Neste estudo, foi possível verificar que as pessoas idosas em ILPIs se utilizam das crenças espirituais/religiosas, e reconhecem que o fazem, para tomar decisões sobre a sua vida, e como suporte, apoio e superação dos eventos estressores.

A religiosidade é central na vida da pessoa idosa institucionalizada, com ênfase na dimensão da prática privada, ou seja, as práticas individuais (por exemplo, a oração) são as mais utilizadas como meio de enfrentamento.

Em tal contexto, pode-se certificar do quanto a pessoa idosa apresenta demandas por cuidados espirituais. A ausência de profissionais com formação, competência e capacidade para tal assistência é evidente: em nenhuma das ILPIs pesquisadas, foi encontrado um profissional que atenda às necessidades espirituais dos idosos institucionalizados. Mesmo assim, cabe ressaltar que é possível a integração dos cuidados espirituais pela equipe multiprofissional nas instituições. Contudo, a integração de um especialista para tal cuidado é o mais indicado, sugere-se que Cuidadores Espirituais tenham preferencialmente formação em Teologia, e ainda com conhecimentos em Bioética.

Percebeu-se também, que embora o estudo tenha confirmado a relevância da $\mathrm{E} / \mathrm{R}$ para a pessoa idosa institucionalizada, ainda há escassez de pesquisas sobre a temática, especificamente no contexto das ILPIs. Por isso, sugere-se que pesquisas complementares sejam realizadas, para uma melhor compreensão.

\section{REFERÊNCIAS}

AGÊNCIA NACIONAL DE VIGILÂNCIA SANITÁRIA. Resolução n. 283, de 26 de setembro de 2005. Aprova o regulamento técnico que define normas de funcionamento 
para as Instituições de longa permanência para idosos, de caráter residencial. ANVISA, 2005. Disponível em:

https://bvsms.saude.gov.br/bvs/saudelegis/anvisa/2005/res0283_26_09_2005.html. Acesso em: 28 jun. 2020.

BRASIL. [Constituição (1988)] Constituição da República Federativa do Brasil de 1988. Brasília: Presidência da República, 1988. Disponível em:

http://www.planalto.gov.br/ccivil_o3/constituicao/constituicao.htm. Acesso em: 10 mar. 2019 .

BRASIL. Lei n. 9.982 de 14 de julho de 2000. Dispõe sobre a prestação de assistência religiosa nas entidades hospitalares públicas e privadas, bem como nos estabelecimentos prisionais civis e militares. Brasília, DF: Presidência da República, [200o]. Disponível em: http://www.planalto.gov.br/ccivil_03/Leis/L9982.htm. Acesso em: 12 jun. 2019.

CAMARANO, A. A.; KANSO, S. As instituições de longa permanência para idosos no Brasil. Revista Brasileira de Estudos de População, Rio de Janeiro, v. 27, n. 1, p. 233-235, 2010. Disponível em: http://www.scielo.br/pdf/rbepop/v27n1/14.pdf. Acesso em: 11 jun. 2019.

DUARTE, F. M.; WANDERLEY, K. S. Religião e espiritualidade de idosos internados em uma enfermaria geriátrica. Psicologia: Teoria e Pesquisa, Brasília, v. 27, n. 1, p. 49-53, 2011. Disponível em: http://www.scielo.br/pdf/ptp/v27n1/a07v27n1.pdf. Acesso em: 10 out. 2019.

ESPERANDIO, M. R. G.; MACHADO, G. A. S. Brazilian physicians Beliefs and attitudes toward patients Spirituality: implications for clinical practice. Journal of Religion and Health, v. 57, p. 1-16. 2018. Available in: https://www.ncbi.nlm.nih.gov/pubmed/30269225. Access in: 10 jun. 2019.

ESPERANDIO, M. R. G. et al. Coping religioso/espiritual na antessala de UTI: reflexões sobre a integração da espiritualidade nos cuidados em saúde. Interações, Belo Horizonte, v. 12, n. 22, p. 303-322, dez. 2017. Disponível em:

http://periodicos.pucminas.br/index.php/interacoes/article/view/P.19832478.2017v12n22p303. Acesso em: 27 set. 2021.

ESPERANDIO, M. R. G. et al. Envelhecimento e espiritualidade: o papel do coping espiritual/religioso em pessoas idosas hospitalizadas. Interação em Psicologia, Curitiba, v. 23, n. 2, 2019. Disponível em:

https://revistas.ufpr.br/psicologia/article/view/65381/o. Acesso em: o8 ago. 2019.

FARIA, J. B.; SEIDL, E. M. F. Religiosidade e enfrentamento em contextos de saúde e doença: Revisão da Literatura. 2005. Psicologia Reflexão e Crítica, Porto Alegre, v. 18, n. 3, p. 381-389, 2005. Disponível em: http://www.scielo.br/pdf/prc/v18n3/a12v18n3.pdf. Acesso em: 16 jun. 2019.

FONTELLES, M. J. et al. Metodologia da pesquisa científica: diretrizes para a elaboração de um protocolo de pesquisa. Revista Paraense de Medicina, Belém, v. 23, n. 3, set. 2009. Disponível em: https://pesquisa.bvsalud.org/portal/resource/pt/lil-588477. Acesso em: 10 out. 2019. 
GHOLAMI, M. et al. Comparison of the effectiveness of mindfulness and spiritual/religious coping skills on health hardiness and somatic complaints of elderly with hypertension. Health, Spirituality and Medical Ethics, Qom/Irã, v. 4, n. 3, p. 19-26, 2017. Available in: http://jhsme.muq.ac.ir/article-1-191-fa.pdf. Access in: 05 mar. 2019.

GOBATTO, C. A.; ARAUJO, T. C. C. F. Coping religioso-espiritual: reflexões e perspectivas para a atuação do psicólogo em oncologia. Revista da Sociedade Brasileira de

Psicologia Hospitar, Rio de Janeiro, v. 13 n. 1, jun. 2010. Disponível em:

http://pepsic.bvsalud.org/scielo.php?script=sci_arttext\&pid=S1516-

08582010000100005. Acesso em: 10 out. 2019.

GOMES, N. S.; FARINA, M.; DAL FORNO, C. Espiritualidade, religiosidade e religião: reflexão de conceitos em artigos psicológicos. Revista de Psicologia da IMED, Passo Fundo, v. 6, n. 2, p. 107-112, 2014. Disponível em:

https://seer.imed.edu.br/index.php/revistapsico/article/view/589. Acesso em: 11 nov. 2019.

GRANGEIRO, A. F. B. et al. Impacto da religiosidade e espiritualidade em pessoas idosas centenárias: revisão sistemática. Ciências Sociais e Religião, Porto Alegre, v. 19, n. 27, p. 173-182, dez. 2017. Disponível em:

https://econtents.bc.unicamp.br/inpec/index.php/csr/article/view/12506. Acesso em: 14 jun. 2019.

HAGHIGHI, F. Correlation between religious coping and depression in cancer patients.

Psychiatria Danubina, Zagreb, v. 25, n. 3, p. 236-240, 2013. Available in:

https://www.ncbi.nlm.nih.gov/pubmed/24048390. Access in: 18 may 2019.

INSTITUTO BRASILEIRO DE GEOGRAFIA E ESTATÍSTICA. Síntese de indicadores sociais: uma análise das condições de vida da população brasileira 2016. Rio de Janeiro: IBGE, 2016. (Estudos e pesquisas. Informação demográfica e socioeconômica, 36).

Disponível em: https://biblioteca.ibge.gov.br/visualizacao/livros/liv98965.pdf. Acesso em: 03 out. 2019.

INSTITUTO DE PESQUISA ECONÔMICA APLICADA. Condições de funcionamento e infraestrutura das instituições de longa permanência para idosos no Brasil. IPEA, 2011. Disponível em:

http://www.ipea.gov.br/portal/index.php?option=com_content\&view=article\&id=8571. Acesso em: 06 jun. 2019.

JUN, J. S. et al. Stress and spirituality on the depressive symptoms of older adults in assisted living: gender differences. Journal of Evidence-informed Social Work, London, v. 12, n. 6, p. 588-600, 2015. Available in:

https://www.academia.edu/30460413/Stress_and_Spirituality_on_the_Depressive_Sym ptoms_of_Older_Adults_in_Assisted_Living_Gender_Differences. Access in: 03 feb. 2019.

KOENIG, H. G. Medicina, religião e saúde: o encontro da ciência e da espiritualidade. Porto Alegre: LP\&M, 2012. 
KOENIG, H. G.; PARGAMENT, K. I.; NIELSEN, J. Religious coping and health status in medically ill hospitalized older adults. The Journal of Nervous and Mental Disease, Baltimore, v. 186, n. 9, p. 513-521, 1998. Available in:

https://journals.lww.com/jonmd/Abstract/1998/o900o/Religious_Coping_and_Health_ Status_in_Medically.1.aspx. Access in: 13 mar. 2019.

LUCCHETTI, G. et al. O idoso e sua espiritualidade: impacto sobre diferentes aspectos do envelhecimento. Revista Brasileira de Geriatria e Gerontologia, Rio de Janeiro, v. 14, n. 1, p. 159-167, 2011. Disponível em:

https://www.scielo.br/scielo.php?script=sci_arttext\&pid=S1809-98232011000100016. Acesso em: 12 jun. 2019.

MINAYO, M. C. S. (org.). Pesquisa social. Teoria, método e criatividade. 32. ed. Petrópolis: Vozes, 2012.

MOREIRA-ALMEIDA, A.; KOENIG, H. G. Retaining the meaning of the words religiousness and spirituality: a commentary on the whogol srpb group's "a cross-cultural study of spirituality, religion, and personal beliefs as components of quality of life". Social Science and Medicine, Boston, v. 63, n. 4, p. 843-845, 2006. Available in: https://www.sciencedirect.com/science/article/pii/So277953606001365. Access in: 14 jun. 2019.

NUNES, D. P. et al. Rastreamento de fragilidade em idosos por instrumento autorreferido. Revista Saúde Pública, São Paulo, v. 49, n. 2, p. 1-9, 2015. Available in: https://www.scielo.br/pdf/rsp/v49/pt_o034-8910-rsp-So034-89102015049005516.pdf. Access in: 29 aug. 2019.

OLIVEIRA, R. M.; ALVES, V. P. A qualidade de vida dos idosos a partir da influência da religiosidade e da espiritualidade: cuidados prestados aos idosos institucionalizados em Caetité (BA). Revista Kairós Gerontologia, São Paulo, v. 17, n. 3, p. 305-327. 2014. Disponível em: https://revistas.pucsp.br/index.php/kairos/article/view/23208. Acesso em: 03 out. 2019.

OLIVEIRA, M. R.; JUNGES, J. R. Saúde mental e espiritualidade/religiosidade: a visão de psicólogos. Estudos de Psicologia, Natal, v. 17, n. 3, p. 469-476, dez. 2012. Disponível em: https://www.scielo.br/scielo.php?script=sci_arttext\&pid=S1413294X2012000300016. Acesso em: 08 abr. 2019.

OLIVEIRA, J. M.; ROZENDO, C. A. Instituição de Longa Permanência para Idosos: um lugar de cuidado para quem não tem opção? Revista Brasileira de Enfermagem, Brasília, v. 67, n. 5, p. 773-779, out. 2014. Disponível em: http://www.scielo.br/pdf/reben/v67n5/o034-7167-reben-67-05-0773.pdf. Acesso em: 11 jun. 2019.

PANZINI, R. G. Escala de Coping religioso-espiritual (Escala CRE): tradução, adaptação e validação da Escala Rcope, abordando relações com saúde e qualidade de vida. 2004. 238 f. Dissertação (Mestrado em Psicologia) - Universidade Federal do Rio Grande do Sul, Porto Alegre, 2004. Disponível em: http://hdl.handle.net/10183/7100. Acesso em: 28 nov. 2018. 
PANZINI, R. G.; BANDEIRA, D. R. Escala de coping religioso-espiritual (Escala CRE): elaboração e validação de construto. Psicologia em Estudo, Maringá, v. 10, n. 3, p. 507516, 2005. Disponível em: https://doi.org/10.1590/S1413-73722005000300019. Acesso em: 22 jul. 2019.

PANZINI, R. G.; BANDEIRA, D. R. Coping religioso/espiritual. Revista de Psiquiatria Clínica, São Paulo, v. 34, p. 126-135, 2007. Disponível em:

https://www.scielo.br/scielo.php?script=sci_arttext\&pid=So101-60832007000700016. Acesso em: 14 fev. 2019.

PARGAMENT, K. I. The psychology of religion and coping: theory, research, practice. Guilford Press, New York, 1997. 548p.

PARGAMENT, K. I. Spirituality as an irreducible human motivation and process. International Journal for the Psychology of Religion, v. 23, n. 4, p. 271281, 2013. Available in: https://psycnet.apa.org/record/2013-32358-004. Access in: 27 sep. 2021.

PARGAMENT, K. I.; KOENIG, H. G.; PEREZ, L. Patterns of positive and negative religious coping with major life stressors. Journal for the Scientific Study of Religion, v. 37, n. 4, p. 710-724, 1998. Available in:

https://www.jstor.org/stable/pdf/1388152.pdf?seq=1\#page_scan_tab_contents. Access in: 18 may 2019.

PARGAMENT, K.I.; KOENIG, H.G.; PEREZ, L. M. The many methods of religious coping: development and initial validation of the RCOPE. Journal of Clinical Psychology, Constanta/Romênia, v. 56, n. 4, p. 519-43, 2000. Available in:

https://www.ncbi.nlm.nih.gov/pubmed/10775045. Access in: 22 jul. 2019.

PERES, J. F. P.; SIMÃO, M. J. P.; NASELLO, A. G. Espiritualidade, religiosidade e psicoterapia. Revista de Psiquiatria Clínica, São Paulo, v. 34, n. 1, p. 136-145, 2007. Disponível em: http://www.scielo.br/scielo.php?script=sci_arttext\&pid=So10160832007000700017. Acesso em: 27 jun. 2019.

REIS, L. A. et al. Perfil sociodemográfico e de saúde do idoso em Instituição de Longa Permanência para Idosos em Vitória da Conquista/BA. InterScientia, João Pessoa, v. 1, n. 3, p. 50-59, dez. 2013. Disponível em:

https://periodicos.unipe.br/index.php/interscientia/article/view/47/44. Acesso em: 11 jun. 2019.

ROCHA, A. C. A. L.; CIOSAK, S. I. Doença crônica no idoso: espiritualidade e enfrentamento. Revista da Escola de Enfermagem da USP, São Paulo, v. 48, n. 2, p. 92-98, 2014. Disponível em: http://www.scielo.br/pdf/reeusp/v48nspe2/pt_oo8o-6234reeusp-48-nspe2-00087.pdf. Acesso em: 12 jun. 2019.

SANTOS, W. J. et al. Enfrentamento da incapacidade funcional por idosos por meio de crenças religiosas. Ciência e Saúde Coletiva, Rio de Janeiro, v. 18, n. 8, p. 2319-2328, 2013. Disponível em: https://www.scielo.br/scielo.php?pid=S141381232013000800016\&script=sci_abstract\&tlng=pt. Acesso em: 15 jun. 2019.

SOUZA, J. N. Cristianismo: a religião do diálogo. São Paulo: Fonte editorial, 2010. 
STECZ, P.; KOCUR, J. Religiousness, religious Coping with illness, and psychological function among polish elderly patients with osteoarthritis undergoing arthroplasty.

Journal of Religion and Health, Constanta/Romênia, v. 54, n. 2, p. 554-70, apr. 2015. Available in: https://www.ncbi.nlm.nih.gov/pubmed/24563370. Access in: 21 dec. 2018.

VITORINO, L. M.; VIANNA, L. A. C. Coping religioso/espiritual de idosos institucionalizados. Acta Paulista de Enfermagem, São Paulo, v. 25, n. 1, p. 136-142, 2012. Disponível em: https://www.scielo.br/scielo.php?pid=So10321002012000800021\&script=sci_arttext\&tlng=pt. Acesso em: 06 jul. 2019.

VITORINO, L. M.; LOW, G.; VIANNA, L. A. C. Linking spiritual and religious coping with the quality of life of community-dwelling older adults and nursing home residents.

Gerontology and Geriatric Medicine, v. 2, p. 1-9, 2016. Available in: https://www.ncbi.nlm.nih.gov/pubmed/28451628. Access in: 18 may 2019.

Recebido em: 12 fev. 2021 Aprovado em: 21 jul. 2021 